\title{
ACETABULAR DYSPLASIA
}

\author{
The Acetabular Angle
}

\author{
Ian K. Sharp, Hull, England
}

Congenital dysplasia of the hip joint, one of the common causes of osteoarthritis of the hip, has as its features deformity of the femoral head, anteversion of the femoral neck, coxa valga and varying degrees of shallow acetabulum (Lloyd-Roberts 1955). Of these, the last is the commonest and probably the most important. The etiology of hip dysplasia has been discussed by Wiberg (1939) and Hart (1952). Various estimates of the frequency of the condition have been made. Lloyd-Roberts (1955) found that 20.9 per cent of arthritic hips were initially dysplastic, Wiberg (1939) reported $25 \cdot 7$ per cent while Gade (1947) attributed no less than 47.9 per cent of his series to this congenital deformity. This difference in estimates is probably due to the difficulty in identifying the primary etiological factor in advanced osteoarthritis.

Wiberg (1939) evolved a radiographic measurement, the $\mathrm{C} / \mathrm{E}$ angle, in his studies of congenital subluxation of the hip. This $\mathrm{C} / \mathrm{E}$ angle is the angle at the intersection of two lines radiating from the centre of the femoral head $(C)$, one passing through the point $(E)$ at the outer edge of the acetabular roof, the other vertical to the transverse axis between $\mathrm{C}$ and the point $\mathrm{C}_{1}$ at the centre of the contralateral femoral head. This angle is a means of locating the femoral head relative to the acetabulum, and also, where the femoral head is not displaced, provides an indication of the degree of development of the acetabular roof. During the course of a study of acetabular dysplasia in the adult, it became clear that the $\mathrm{C} / \mathrm{E}$ angle did not provide an accurate measurement of this condition for the following reasons: 1) the centre point of a deformed femoral head cannot be located accurately; 2) subluxation, or simple loss of joint space, alters the $\mathrm{C} / \mathrm{E}$ angle, giving false readings; and 3) subluxation of the contralateral hip also affects the $\mathrm{C} / \mathrm{E}$ angle.

It is strictly correct to consider the entire hip joint in a study of dysplasia. Nevertheless, the feature which is constantly present is the underdevelopment of the acetabular roof, where the surface available for weight bearing is smaller than normal and therefore subject to proportionately greater pressure. A simple measurement of the acetabulum alone, without reference to the head of the femur, appears to provide a logical and possibly more accurate approach.

\section{THE ACETABULAR ANGLE}

In the radiograph of the normal acetabulum only two points lend themselves readily to mensuration, namely the lateral edge of the acetabular roof and the inferior tip of the U-figure or " pelvic tear drop." Using these two points and the horizontal line between the U-figures, the angle of inclination of the acetabulum can be measured-the acetabular angle. Of the components of this measurement, the lateral edge of the acetabular roof is the more obvious. It must be remembered, however, that this is not a fixed point on the skeleton but is in fact the radiographic projection of a ridge of bone running antero-posteriorly, more or less parallel with the x-ray beam. Similarly, the U-figure is the end-on projection of a bony ridge, the floor of the acetabular fossa. Werndorff (quoted by Wiberg 1939) made the U-figure disappear by sawing away this bony plate. Vare (1952) succeeded in outlining it by means of a flat strip of lead foil applied to the acetabular fossa and curving round the inferior margin of this, up over the inner wall of the lesser pelvis as far as the ilio-pectineal eminence. It follows that the position of the two points from which the acetabular angle is measured must vary on the radiograph with any pelvic tilt. To discover the degree of error, strips of lead foil were applied to the acetabula of a macerated pelvis to outline the U-figure as described by Vare and films were taken with 
the pelvis in various positions. The tube-film distance was 100 centimetres and the beam was centred 5 centimetres cephalad to the symphysis pubis, which is a standard technique for pelvic radiography.

The views taken were: 1) Symphysis and both anterior superior iliac spines in the same horizontal plane. 2) Anterior superior iliac spines level, symphysis high: pelvis tilted forward 15 degrees. 3) Anterior superior iliac spines level, symphysis low: pelvis tilted backward 15 degrees. 4) Symphysis level with mid-point of interspinous line: right anterior superior iliac spine farther forward than left: pelvis tilted 10 degrees to left. 5) As in position 4, but with pelvis tilted 10 degrees to right.

TABLE I

The Variation due to Radiographic

DISTORTION

\begin{tabular}{|ccc|}
\hline \multirow{2}{*}{ Position } & \multicolumn{2}{c|}{ Acetabular angle (degrees) } \\
\cline { 2 - 3 } & $\frac{\text { Right }}{36}$ & $\frac{40}{\text { Left }}$ \\
\hline 1 & 37 & 41 \\
2 & 35 & 39 \\
3 & 38 & 37 \\
4 & $34 \cdot 5$ & 40 \\
\hline
\end{tabular}

The results are shown in Table I. It will be seen that the variation in the angles resulting from what would be, in clinical radiography, extremely bad positioning is no more than 4 degrees. The second and third positions are, of course, also reproducible by aiming the beam above or below the correct point 5 centimetres above the symphysis. Since the tube-symphysis distance is approximately 70 centimetres, in order to produce the effect of 15 degrees pelvic tilt it would be necessary to centre the beam nearly 20 centimetres above or below the correct point. For measurement, any film so badly centred, or in which there was obvious gross lateral tilting, would be discarded.

In order to check this further, three patients had pelvic views taken in positions 4 and 5 , and in each case the acetabular angle varied less than 2 degrees. Furthermore, among the normal series were a few patients who had several films taken of the pelvis, often at considerable intervals, and in these the acetabular angles were absolutely constant, showing how well standardised is the technique, even in the hands of different radiographers.

\section{THE NORMAL RANGE}

Wiberg (1939) considered that only hips which were functionally blameless could justifiably be included in a normal series. He therefore measured his angle on the radiographs of fifty men and fifty women whose hip joints were clinically normal. These subjects were between the ages of twenty and thirty-five, and he admitted that they might include mal-developed acetabula which had not yet produced symptoms. This objection cannot be dismissed; a radiological measurement would be better to have a radiologically determined base-line.

A good hip joint should last a man throughout his lifetime. Nevertheless, for purely practical reasons an arbitrary lower age limit of sixty was chosen and from the files of the Radiology Department films of fifty male and fifty female pelves with no radiological evidence of osteoarthritis were measured, making a total of 200 hip joints. Apart from the rejection of obviously distorted views no selection was made, the films having been taken for various reasons-fracture or suspected fracture, suspected pelvic metastases, etc. 
The normal range of acetabular angle is shown in Figure 1. The angle was found to be essentially the same in men and women, a surprising finding in view of the well known sex difference in the pelvic conformation. It will be seen from the graph that the normal angles fall within a narrow range. The variation in normals is demonstrated in Figures 2 to 4 , where the angles are respectively the lowest, the average and the highest in the series: Figure 5 illustrates the angle in a typical congenital subluxation. Figures 2 and 3 need no further

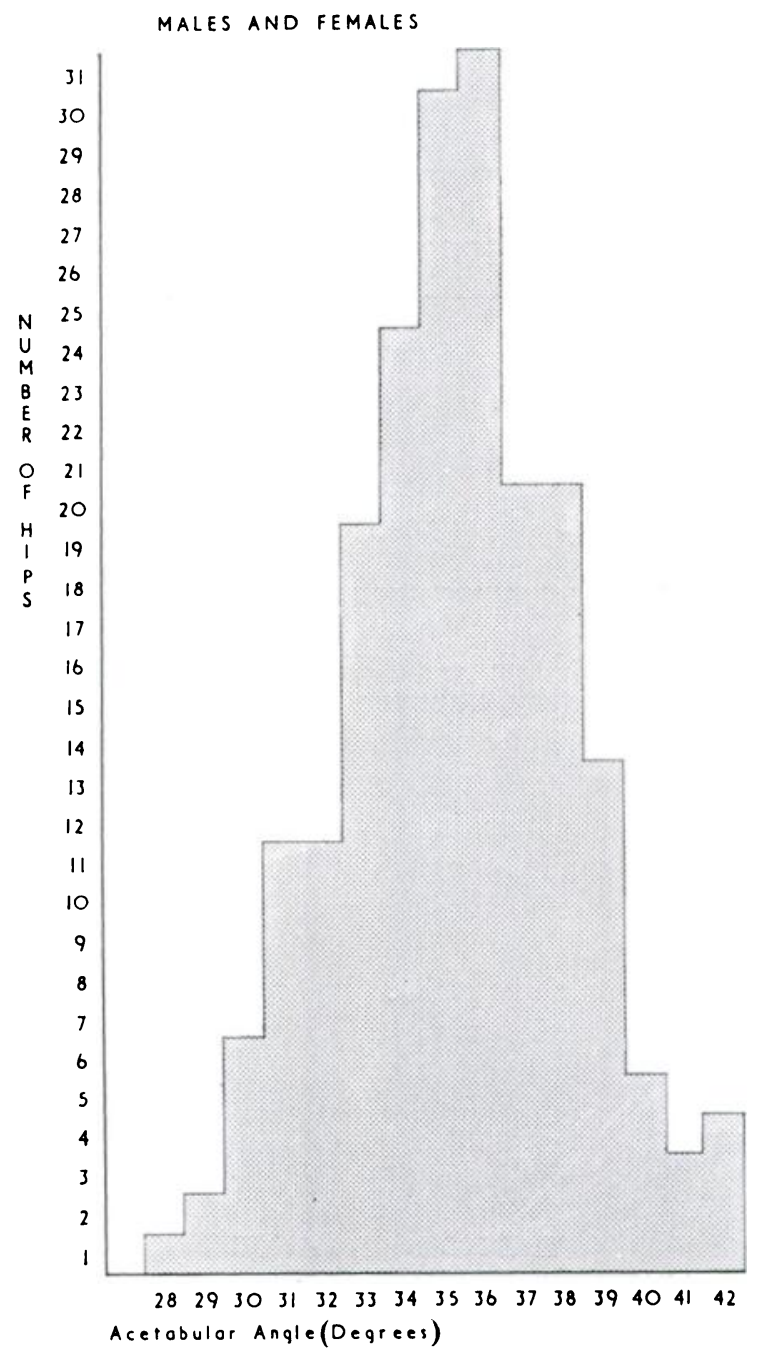

Fig. 1

The angles in the 200 hip joints aggregated.

consideration, but Figure 4 illustrates a pair of acetabula with angles of 42 degrees. It will be seen that the depth of these is such that the relatively small femoral heads are adequately supported. This demonstrates the major theoretical objection to the validity of the acetabular angle, that it does not measure the depth of the acetabulum. In practice, however, the angle of slope of the acetabulum appears to bear a fairly constant relationship to its depth, and this simple measurement provides an excellent index of the degree of acetabular development. 


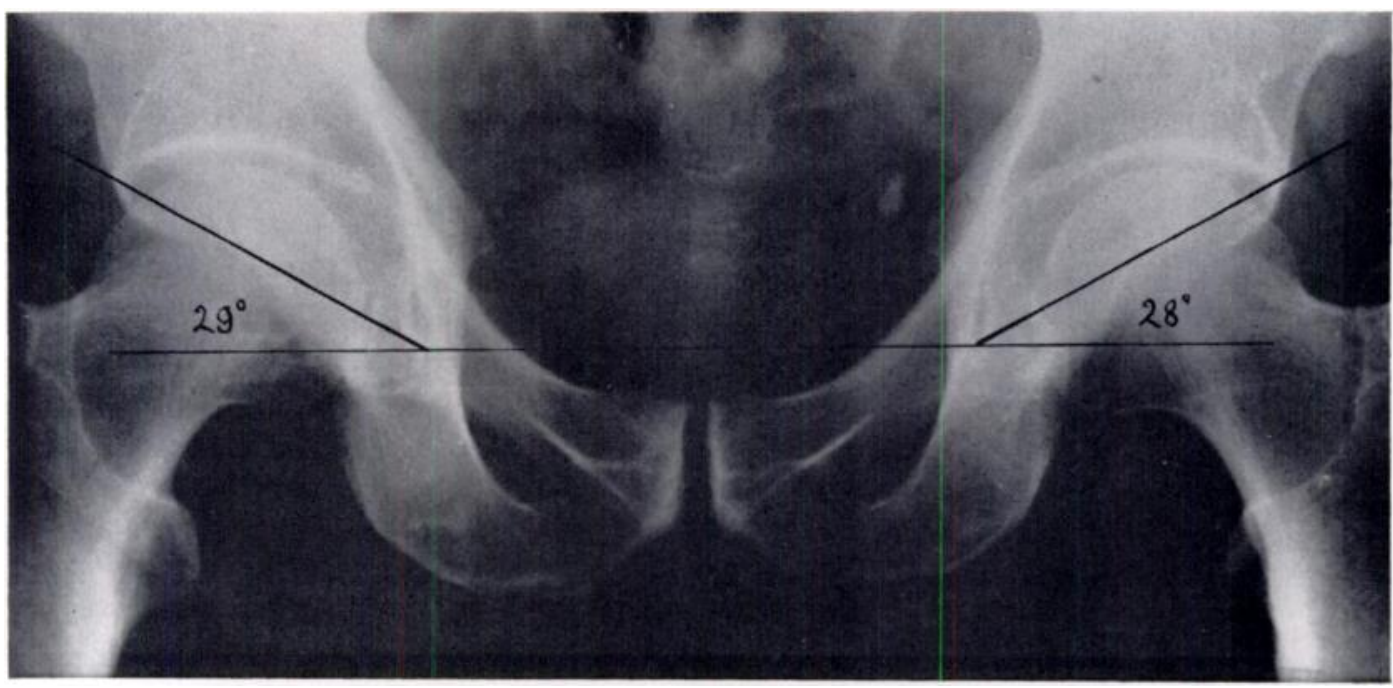

FIG. 2

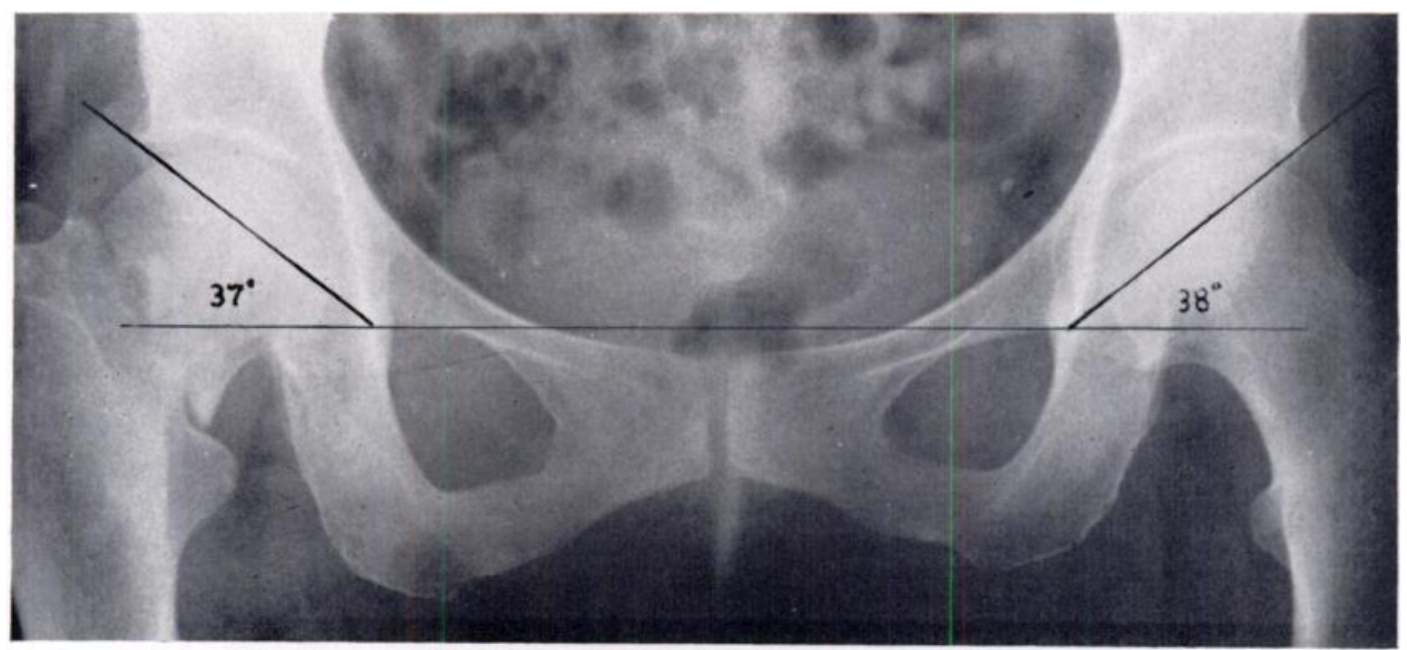

Fig. 3

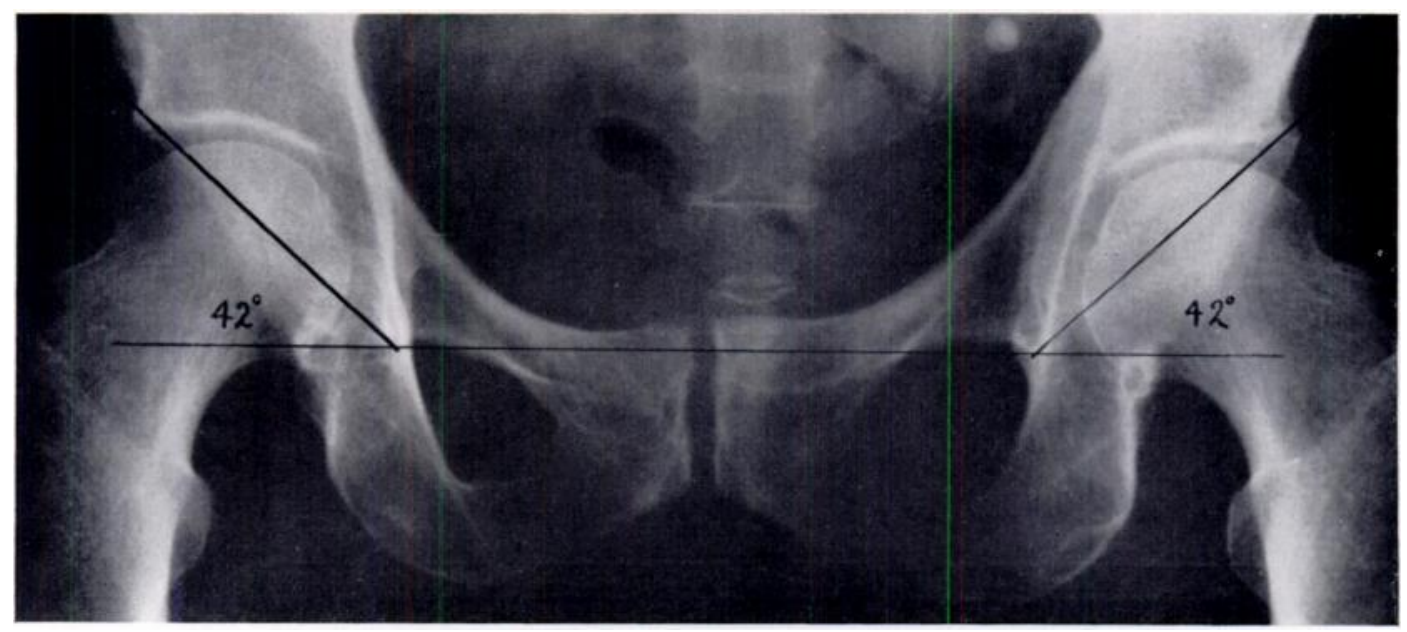

Fig. 4

Three films from the normal series illustrating low, average and high angles.

VOL. 43 B, NO. 2, MAY 1961 


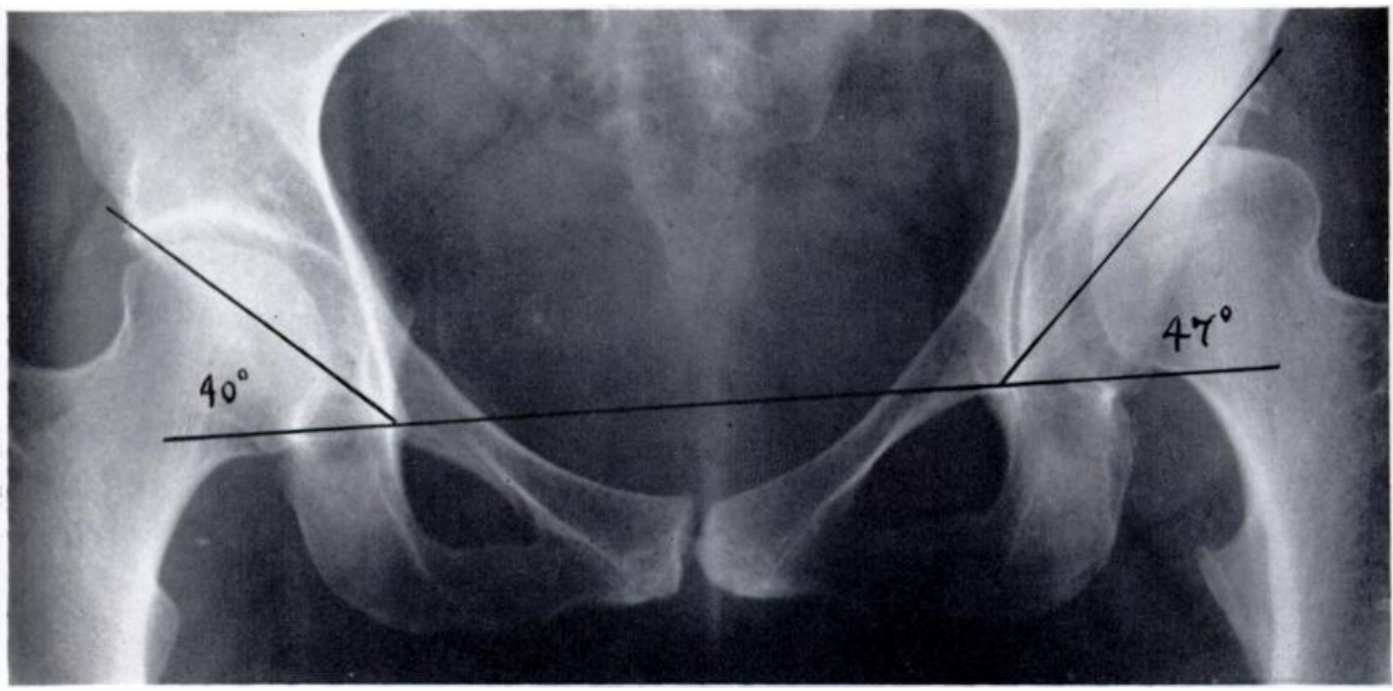

Fig. 5

Congenital subluxation of the hip. Shenton's line is just broken and the acetabular angle is 47 degrees.

\section{SUMMARY AND CONCLUSIONS}

A simple method of measuring the degree of acetabular development in the radiograph of the adult pelvis is described and arguments for its validity are advanced. This measurement is referred to as the acetabular angle. The normal values for this angle are between 33 and 38 degrees. Angles below 32 degrees are uncommon and probably of no clinical significance, whereas angles from 39 to 42 degrees are in the upper limit of normality. An angle of 47 degrees is shown in a hip with congenital subluxation. The prognosis for hip joints with acetabular angles between 42 and 47 degrees is under investigation.

\section{REFERENCES}

Gade, H. G. (1947): A Contribution to the Surgical Treatment of Osteoarthritis of the Hip-Joint. Acta Chirurgica Scandinavica, 95, Supplementum 120.

Hart, V. L. (1952): Congenital Dysplasia of the Hip Joint and Sequelae. Springfield, Illinois: Charles C. Thomas. Lloyd-Rober TS, G. C. (1955): Osteoarthritis of the Hip. Journal of Bone and Joint Surgery, 37-B, 8.

VARE, V. B., Jun. (1952): The Anatomy of the Pelvic Tear Figure. Journal of Bone and Joint Surgery, 34-A, 167.

WIBERG, G. (1939): Studies on Dysplastic Acetabula and Congenital Subluxation of the Hip Joint. Acta Chirurgica Scandinavica, 83, Supplementum 58. 